\title{
The Application of the Microwave Plasma Ionization Source in Ambient Mass Spectrometry
}

\author{
Maria Guć ${ }^{1}$ Edward Reszke ${ }^{2}$ Michał Cegłowski ${ }^{1} \cdot$ Grzegorz Schroeder $^{1}$
}

Received: 13 March 2019 / Accepted: 5 April 2019 / Published online: 20 April 2019

(c) The Author(s) 2019

\begin{abstract}
A new direct-current microwave argon plasma source was designed and constructed for use in mass spectrometry. Solid samples and analytes on solid materials were examined by means of mass spectrometry. The microwave source was used to generate argon plasma allowing the ionization of analyte particles thermally released from the heated crucible whose temperature could be regulated from 100 to $250{ }^{\circ} \mathrm{C}$. A microwave argon plasma ionization source in ambient mass spectrometry was used for analysis of pure compounds, analytes in molecular imprinted polymers (MIPs) and drugs in medical tablets. Results suggest that ionization occurred mainly through protonation, with only a small contribution of fragmentation and adduct formation. In this technique, ion fragmentation analysis $\left(\mathrm{MS}^{2}\right)$ gives good results in the analysis of low molecular weight compounds in complex matrices. Limits of detection and limit of quantification for several small organic molecules were determined for investigation of the analytes in difficult matrixes.
\end{abstract}

Keywords Microwave argon plasma $\cdot$ Mass spectrometry $\cdot$ Chemical analysis $\cdot$ Molecular imprinted polymers $\cdot$ Drugs in medical tablets

\section{Introduction}

For many years attempts have been made to design a system in which a mass spectrometer would have an independent external source of sample ionization working under atmospheric pressure. In the commercial mass spectrometers the most popular technique of sample ionization is the direct analysis in real time (DART). In this technique ions are produced electronically or vibronically from excited-state species in gases such as helium, argon, or nitrogen that ionize atmospheric molecules or dopant molecules [1-6]. The ions generated from atmospheric or dopant molecules undergo ion-molecule reactions with the sample molecules to produce analyte ions. DART has been successfully used for analysis

Maria Guć

maria.guc@amu.edu.pl

1 Faculty of Chemistry, Adam Mickiewicz University in Poznań, Umultowska 89b, 61-614 Poznań, Poland

2 ERTEC-Poland, Rogowska 146/5, 54-440 Wrocław, Poland 
of chemicals, including chemical agents, pharmaceutics, metabolites, pesticides and environmentally significant compounds.

Flowing atmospheric pressure afterglow mass spectrometry (FAPA) is an analytical chemistry technique for sensitive detection of low molecular weight organic compounds [7-13]. The method of analysis of organic compounds by mass spectrometry with the flowing atmospheric pressure afterglow ion source in the ambient atmosphere and has been proven to be a promising tool for direct and rapid determination of numerous compounds. The construction of the argon plasma torch and its operating parameters have a direct impact on the quality of the spectra obtained in the mass spectrometer. Argon plasma is generated between the two electrodes inside the quartz tube. The first electrode is inside quartz tube and the second electrode is outside at the end of the quartz tube. The analytes were thermally desorbed and ionized by FAPA and identified in the mass spectrometer analyzer. Thermal desorption of analytes is a specific method of introducing a sample into a plasma stream. The order of release of the compounds depends on their volatility. The method offers fast and reliable structural information, with no need of pre-separation, and can be an alternative to the Electron Impact, GC/MS, and ESI for fast analysis of organic compounds.

Zeiri et al. [14] have presented a direct-current microplasma-based flowing atmospheric pressure afterglow for the use in ambient desorption-ionization mass spectrometry. The annular-shaped microplasma is formed in helium between two concentric stainless-steel capillaries that are separated by an alumina tube. Their results suggested that ionization occurred mainly through protonation, with only a small contribution of fragmentation and adduct formation. Limits of detection for several small organic molecules were in the subpicomole range. Dai et al. [15] have demonstrated the application of a microwave induced plasma ionization (MIPI) source to ion mobility spectrometry (IMS). The MIPI source is composed of a copper cavity and a hollow quartz discharge tube. MIPI-IMS was used to detect some volatile organic compounds in monitoring of air pollutants.

The compact microwave discharge, termed the microstrip plasma (MSP) that was previously used for optical emission spectrometry has been used as an afterglow ion source for mass spectrometry by Pfeuffer et al. [16]. The primary background ions present in the afterglow were the ionized and protonated water clusters. An exponential dilution chamber was used to introduce volatile organic compounds into the MSP and yielded limits of detection in the 40-7 ppm range (v/v). The MSP afterglow was found capable of desorption and ionization of analyte species directly from a solid substrate, which suggested its possible use as an ion source for ambient desorption/ionization mass spectrometry.

We present the construction and application of a new microwave argon plasma torch which was designed to be used in the ion trap mass spectrometry. The application of this technique is presented on the example of analysis of pure compounds, analytes included in molecularly imprinted polymers (MIPs) and commercial drugs in the form of tablets.

\section{Experimental}

\section{Instruments}

MS and $\mathrm{MS}^{\mathrm{n}}$ spectra were recorded using an amaZon SL ion trap (Bruker, Bremen, Germany) equipped with an electrospray ion source in infusion mode or microwave argon plasma. The apparatus was operated using the so-called "enhanced resolution mode" (mass 
range: $50-2,200 \mathrm{~m} / \mathrm{z}$, scanning rate: $8100 \mathrm{~m} / \mathrm{z}$ per s). The typical ESI-MS source settings were found to be optimal also for the microwave ionization source, with the exception of the mass spectrometer entrance glass capillary voltage, which was lower $1(1 \mathrm{kV})$ than the standard ESI setting $(4.5 \mathrm{kV})$. The temperature of the glass capillary was set to $200{ }^{\circ} \mathrm{C}$, the drying gas flow was maintained at $3 \mathrm{~L} \mathrm{~min}^{-1}$. The mass spectrometer was operating in the positive ion mode. For $\mathrm{MS}^{2}$ experiments, the isolation width was set to $2 \mathrm{~m} / \mathrm{z}$ and the fragmentation amplitude was in the range from 0.5 to 0.8 unit. The microwave argon plasma ionization source was positioned on the axis of the inlet of the mass spectrometer with the tip located ca. $50 \mathrm{~mm}$ from the MS inlet. The vapors generated in such a way were directly introduced into the argon plasma jet stream, which resulted in their ionization. The overall average time of analysis was ca. $5 \mathrm{~min}$. The mass spectrometer was equipped optionally in an outside microwave argon plasma source (Fig. 1). The microwaves were used to generate argon plasma allowing the ionization of analyte particles thermally released from the heated crucible whose temperature could be changed from 100 to $250{ }^{\circ} \mathrm{C}$, with a temperature increase rate of $3{ }^{\circ} \mathrm{C} \mathrm{s}^{-1}$. The mini crucible allowing the temperature-controlled desorption was placed ca. $10 \mathrm{~mm}$ below the ion stream. The temperature of the compounds desorption was $200 \pm 10{ }^{\circ} \mathrm{C}$.

Argon plasma torch, made of a $4 / 2 \mathrm{~mm}$ diameter (DIA) quartz tube through which argon was flown at the rate of ca. $100 \mathrm{ml} \mathrm{min}^{-1}$, powered by a $100 \mathrm{~W} / 2450 \mathrm{MHz}$ microwave power generator. The impedance tuning is accomplished using a dual dielectric tuner that tunes to the maximum discharge volume and stability. The argon plasma cavity (quarter wavelength, ca. $3 \mathrm{~cm}$ ) is made of stainless steel. The diameter of the external screen is $10 \mathrm{~mm}$, and the total length of the resonator section is $4 \mathrm{~cm}$. The construction of the argon plasma source is shown in Fig. 2.

\section{Materials and Chemicals}

The compounds used in the studies are presented in Table 1. The compounds were purchased from Sigma-Aldrich (St Louis, MO, USA).

Molecularly imprinted polymers (MIPs) are those that have been processed using the molecular imprinting technique, which leaves cavities in the polymer matrix strictly corresponding to a particular template molecule. All reagents used for the synthesis of MIPs were commercial products. Atrazine, pendimethalin, acrylic acid (AA), methacrylic acid (MAA), ethylene glycol dimethacrylate (EGDMA), 2,2'-azobisisobutyronitrile solution $0.2 \mathrm{M}$ in toluene (AIBN), Aluminum Oxide Activated, basic, 4 Brockman I, and

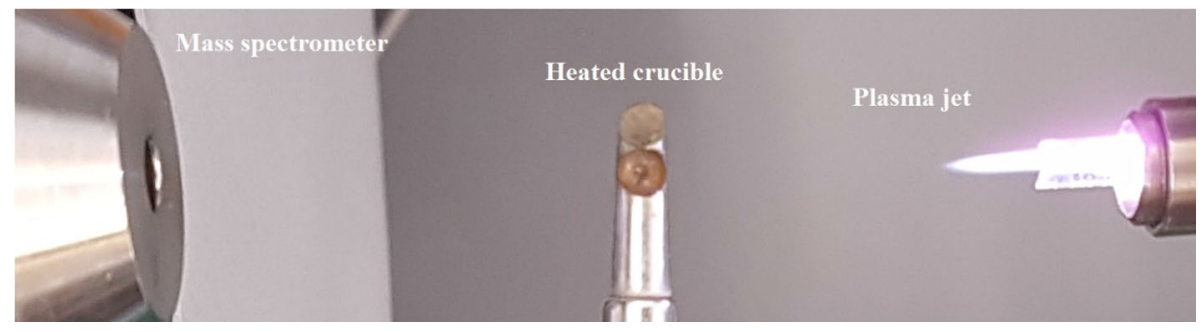

Fig. 1 The measuring system: microwave argon plasma ionization source, heated crucible and amaZon SL mass spectrometer 

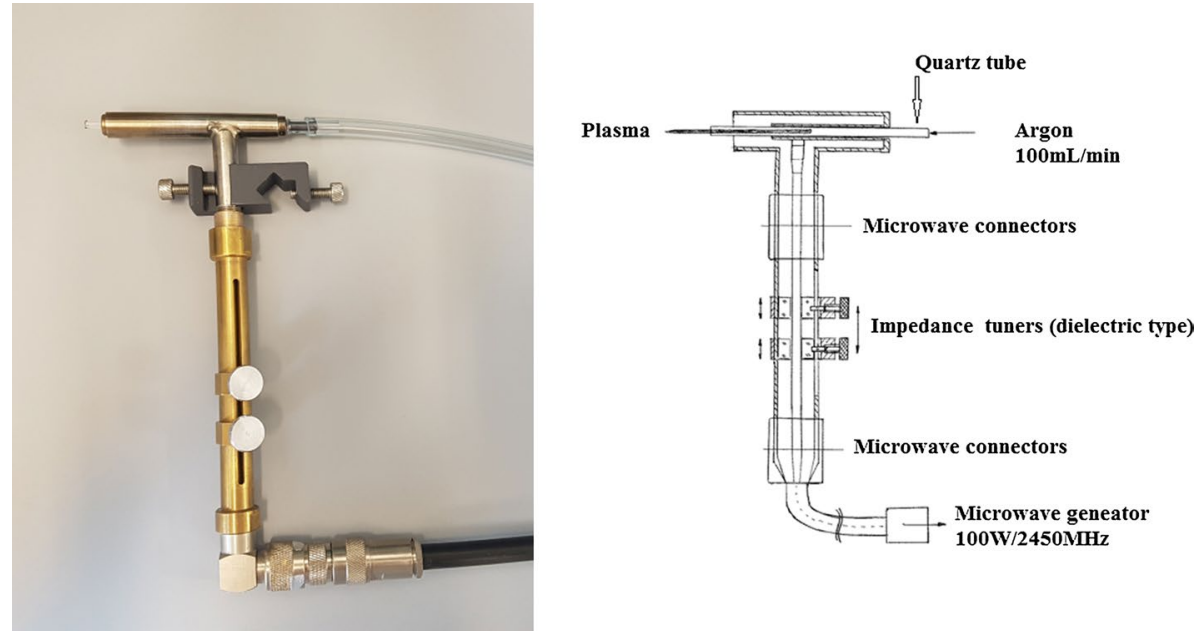

Fig. 2 The construction of the argon plasma source

chloroform solvent were of the p.a. grade were obtained from Sigma-Aldrich (St. Louis, MO, USA).

\section{Synthesis of Atrazine-MIP, Quercetin-MIP and Pendimethalin-MIP}

A portion of $0.4 \mathrm{mmol}$ of the template molecule-atrazine and $1.6 \mathrm{mmol}$ functional monomer-MAA were dissolved in $25 \mathrm{ml}$ of methanol, while $0.6 \mathrm{mmol}$ of the template molecule-pendimethalin and $2.4 \mathrm{mmol}$ the same functional monomer were dissolved in $10 \mathrm{ml}$ chloroform. A portion of $1 \mathrm{mmol}$ of the template molecule-quercetin and $4 \mathrm{mmol}$ functional monomer-AA were dissolved in a mixture of $5 \mathrm{ml}$ chloroform and $5 \mathrm{ml}$ DMF. Subsequently, previously purified with Aluminum Oxide Activated, basic, Brockman I, $8 \mathrm{mmol}$ or $12 \mathrm{mmol}$ cross-linking agent-EGDMA was added. The ratio of the template:monomer:cross-linking agent was 1:4:20, respectively. The pre-polymerization solution was sonicated and purged with nitrogen for $20 \mathrm{~min}$. Afterwards, $0.5 \mathrm{ml}$ or $1 \mathrm{ml}$ initiator-AIBN was added. The tube was sonicated and purged with nitrogen for additional $20 \mathrm{~min}$, sealed and placed in an oven for $24 \mathrm{~h}$ at $60{ }^{\circ} \mathrm{C}$. After polymerization, MIPs were dried under reduced pressure, and ground using mortar and pestle. The particles of used templates were extracted with a mixture of ethanol and acetic acid $(9: 1, \mathrm{v}: \mathrm{v})$ via Soxhlet extraction for $90 \mathrm{~h}$. Then, the final product MIPs was dried at $60{ }^{\circ} \mathrm{C}$ under vacuum and ground. The structure of MIP is presented in Fig. 3.

In order to confirm the binding of analytes in the polymer structures, FT-IR and TG analysis were performed. The concentration of the analytes in the obtained MIPs was $48 \mathrm{mg} / 1 \mathrm{~g}$ of atrazine, $101 \mathrm{mg} / 1 \mathrm{~g}$ of quercetin and $71 \mathrm{mg} / 1 \mathrm{~g}$ of pendimethalin.

\section{Synthesis of NIPs}

As a control experiment, non-imprinted polymers (NIPs), with no templates during the polymerization, were also prepared and treated in the identical manner. 
Table 1 The compounds studied

\begin{tabular}{ll}
\hline Compounds & $\begin{array}{l}\text { Molecular Structure } \\
\text { weight }(\mathrm{g} / \\
\text { mol })\end{array}$ \\
\hline
\end{tabular}

Theophylline

Caffeine

Quinine

Atrazine

Pendimethalin

Quercetin

Ketoprofen 2-(3-benzoylphenyl)propionic acid

Propyphenazone
281.31

302.23<smiles>O=c1c(O)c(-c2ccc(O)c(O)c2)oc2cc(O)cc(O)c12</smiles>

254.28<smiles>CC(C(=O)O)c1cccc(C(=O)c2ccccc2)c1</smiles>

230.30<smiles>Cn1c(=O)c2nc[nH]c2n(C)c1=O</smiles>

194.19<smiles>Cn1c(=O)c2c(ncn2C)n(C)c1=O</smiles><smiles>C=CCN1CCC1C(O)c1ccnc2ccc(OC)cc12</smiles><smiles>CCNc1nc(Cl)nc(NC(C)C)n1</smiles><smiles>CCC(CC)Nc1c([N+](=O)[O-])cc(C)c(C)c1[N+](=O)[O-]</smiles><smiles>Cc1c(C(C)C)c(=O)n(-c2ccccc2)n1C</smiles> 
Table 1 (continued)

\begin{tabular}{ll}
\hline Compounds & $\begin{array}{l}\text { Molecular } \\
\text { weight }(\mathrm{g} / \\
\text { mol) }\end{array}$ \\
$\begin{array}{l}\text { Bisoprolol 1-[4-[[2-(1-methylethoxy)ethoxy]- } \\
\text { methyl]phenoxy]-3-[(1-methylethyl)- amino]- }\end{array}$ \\
$\begin{array}{l}\text { 2-propanol } \\
\text { S- }\end{array}$
\end{tabular}

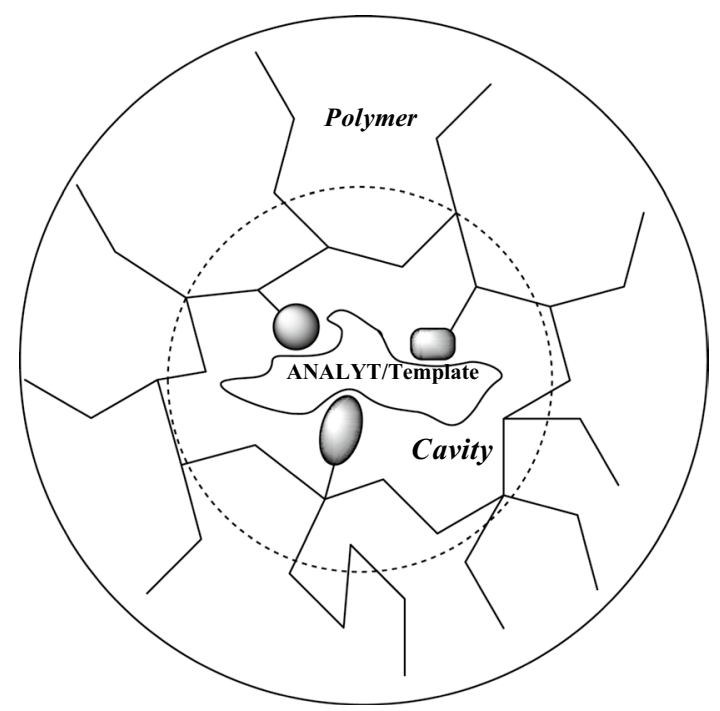

Fig. 3 The structure of analyte/template-MIP

\section{LOD Determination Procedure}

The results of microwave argon plasma ionization source-MS experiments, obtained with the use of a solution of pure analytes, analyte-MIPs, and bioanalytes in medical tablets, were used for evaluation of the work of the new measurement system. All experiments were repeated three times. The relative standard deviation (RSD) obtained for all data did not exceed $20 \%$. In order to determine the background signals, the spectra of particular matrices (NIPs) without the analytes were recorded. The limit of detection (LOD) is the concentration of a substance below which the identity of the substance cannot be distinguished from analytical artefacts. The limit of detection (LOD) was calculated according to the definition: $\mathrm{LOD}=$ mean blank value $+3 \times$ standard deviation. The signal $\mathrm{m} / \mathrm{z}$ analyte was three times higher than the noise level. In the experiments in which the LOD of pure compounds was determined, $20 \mu \mathrm{L}$ of the solution of the analytes at different concentrations in methanol was introduced into the crucible and heated to about $200{ }^{\circ} \mathrm{C}$, whereas in the case of composite matrices, $100 \mathrm{mg}$ of the mixture of MIP/NIP or tablets/NIP with different concentrations of the analytes were introduced into the crucible and also heated to ca. $200{ }^{\circ} \mathrm{C}$. 
The limit of quantification (LOQ) is the concentration of a substance below which the concentration cannot be determined with an acceptable accuracy. The LOQ value was calculated as $\mathrm{LOQ}=3 \times \mathrm{LOD}$.

\section{Results and Discussion}

To assess the application of the microwave argon plasma source in mass spectrometry analysis we used the following pure compounds: theophylline, caffeine and quinine. Theophylline is a methylxanthine drug used in the therapy of respiratory problems and asthma under a variety of brand names. Theophylline bears structural and pharmacological similarity to

(a)

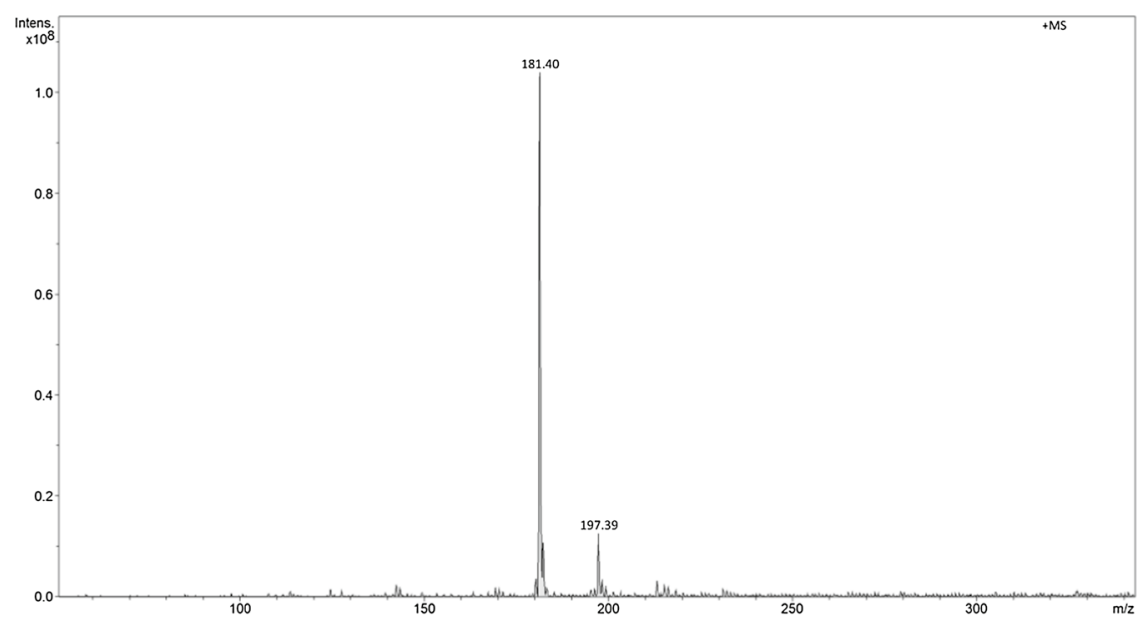

(b)

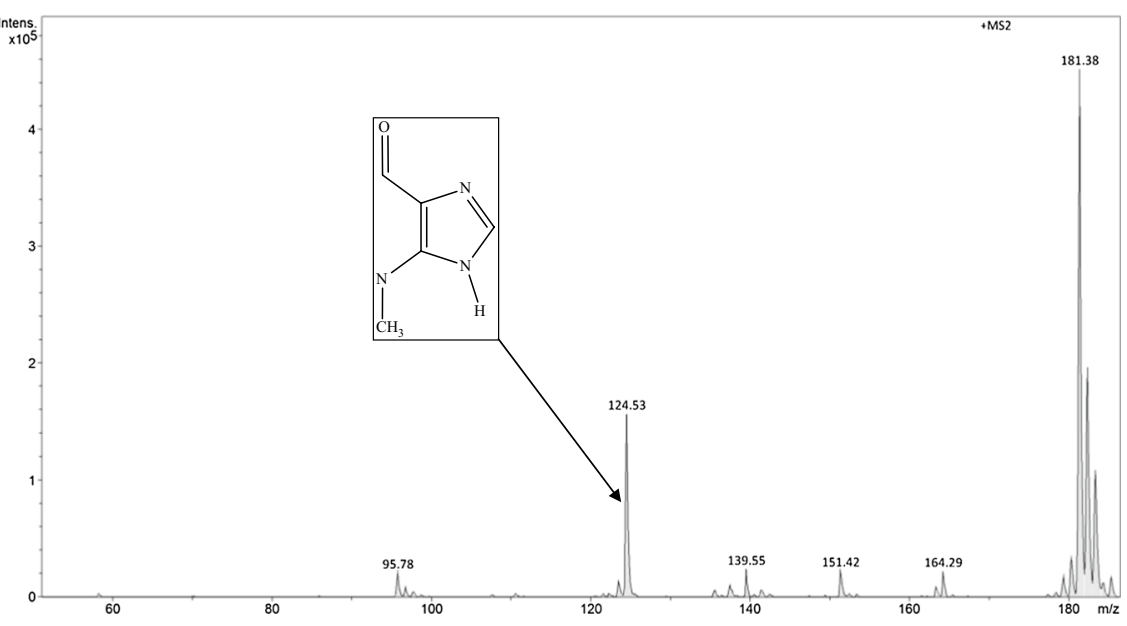

Fig. 4 The microwave argon plasma source-MS (positive ions) spectrum (a) and fragmentation $\left(\mathrm{MS}^{2}\right) \mathrm{spec}^{-}$ trum of theophylline (b) 
theobromine and caffeine, and it is readily found in in tea and cocoa. Caffeine stimulates nervous system and reversibly blocks the action of adenosine on its receptor and consequently prevents the onset of drowsiness induced by adenosine. Quinine is a medication used to treat malaria and babesiosis. Quinine is also an ingredient of tonic water that gives it its bitter taste.

In order to determine the suitability of the method for analysis of functional polymers, MIPs containing in their structure the analytes atrazine, pendimethalin and quercetin trapped in the cavities were obtained. Atrazine is a herbicide of the triazine class used in preemergence and postemergence applications. Pendimethalin is an herbicide used to control annual grasses and certain broadleaf plants. Quercetin is a plant flavonol found in many fruit, vegetables, leaves, and grains.

The third group of materials used for testing was that of active ingredients contained in commercial drugs in the form of tablets. Ketoprofen is one of the propionic acid class

(a)

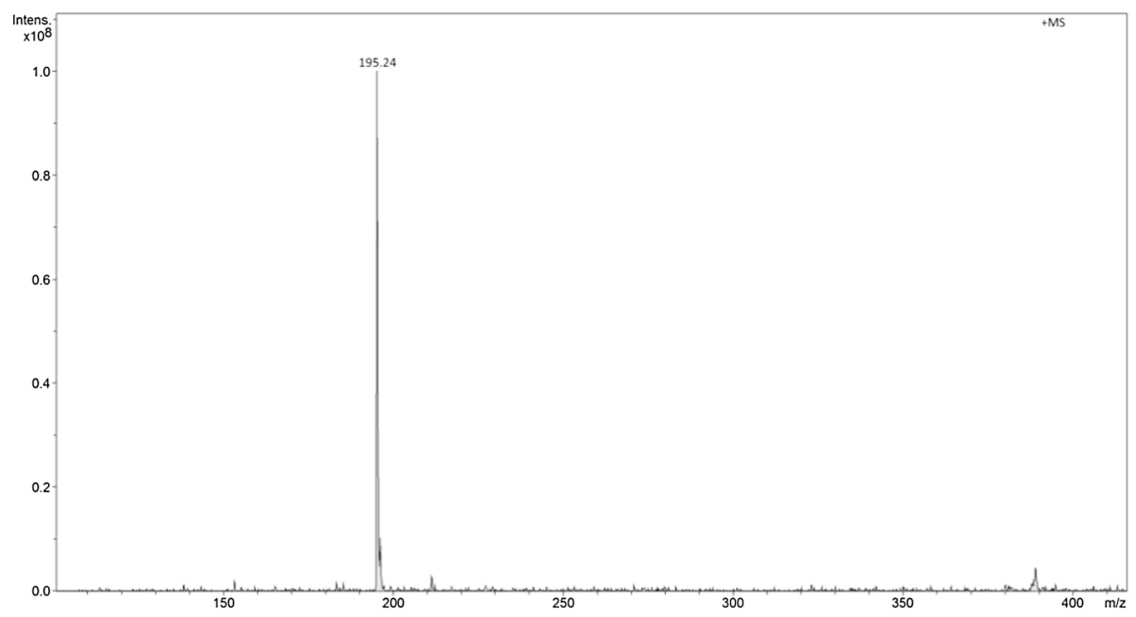

(b)

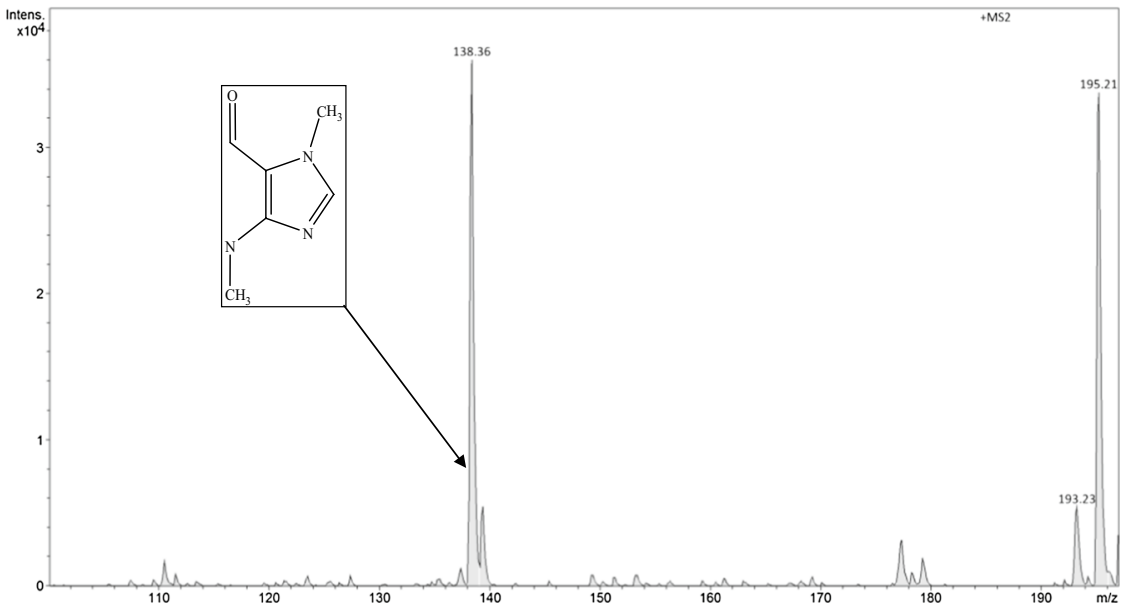

Fig. 5 The microwave argon plasma source-MS (positive ions) spectrum (a) and fragmentation $\left(\mathrm{MS}^{2}\right) \mathrm{spec}^{-}$ trum of caffeine $(\mathbf{b})$ 
of nonsteroidal anti-inflammatory drugs with analgesic and antipyretic effects. It acts by inhibiting the body's production of prostaglandin. Propyphenazone is a derivative of phenazone with similar analgesic and antipyretic effects, while bisoprolol is used specifically in the treatment of hypertension and heart failure.

The first groups of analyzed systems were pure compounds. The microwave argon plasma ionization source-MS spectra as well as $\mathrm{MS}^{2}$ spectra were analyzed for this group of compounds (Figs. 4, 5 and 6). For all analyzed low molecular weight compounds in the positive ion spectrum, the $\mathrm{m} / \mathrm{z}$ signals $[\mathrm{M}+\mathrm{H}]^{+}$were recorded, whereas in the $\mathrm{MS}^{2}$ spectra the main decay product of this ion was recorded.

The second group of analyzed compounds included MIPs containing the analytes in their structure. Molecularly imprinted polymers are the polymeric matrices obtained using the imprinting technology for defined analytes, useful to separate and analyze complicated

(a)

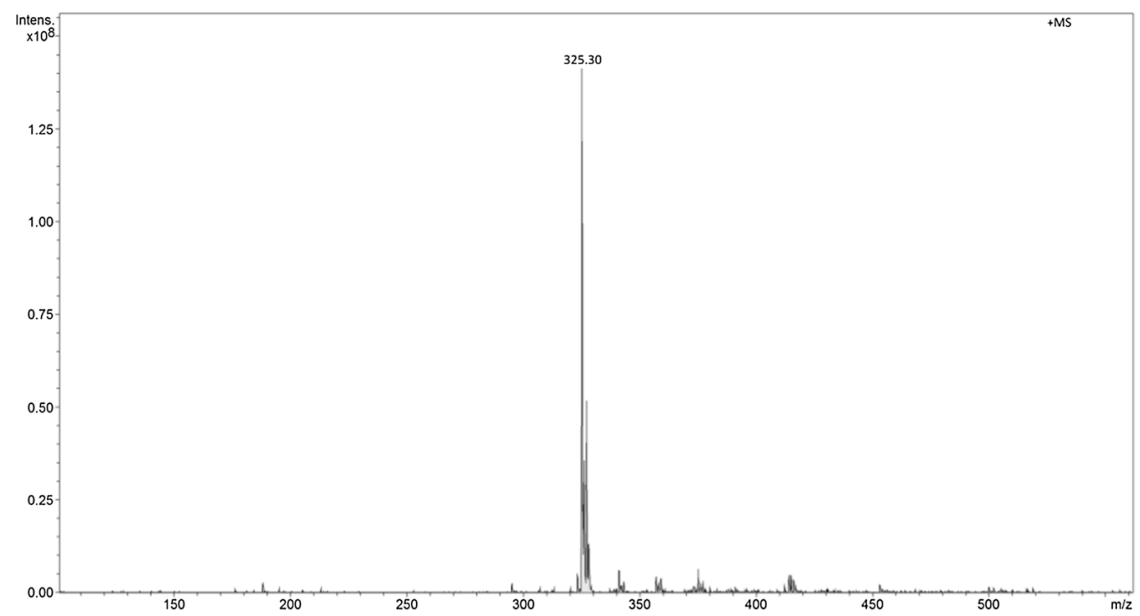

(b)

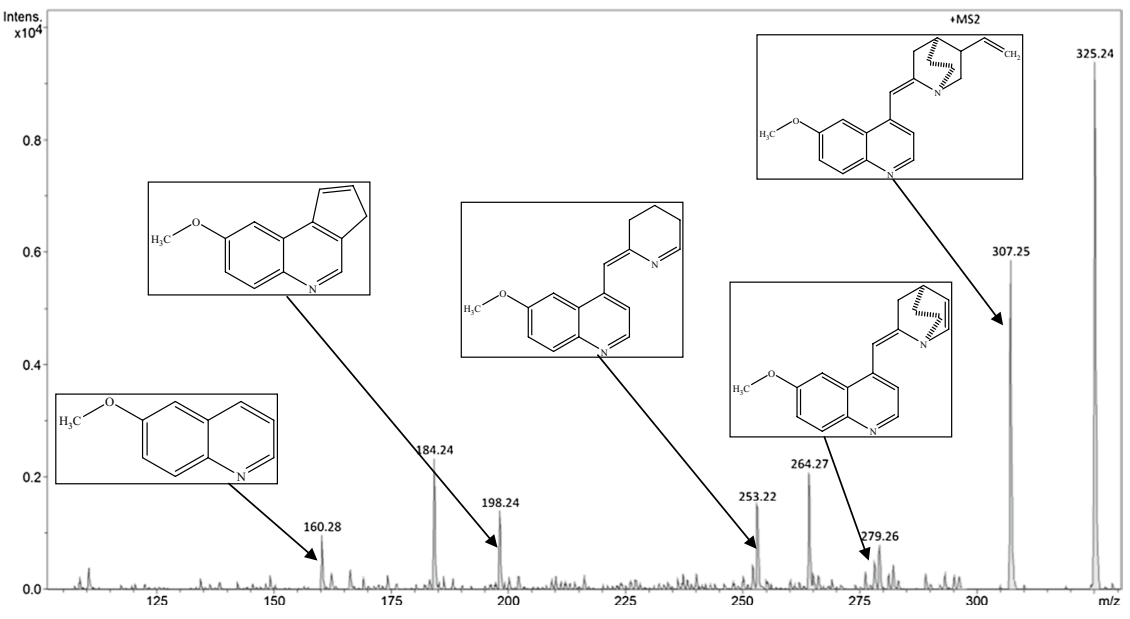

Fig. 6 The microwave argon plasma source-MS (positive ions) spectrum (a) and fragmentation (MS ${ }^{2}$ ) spectrum of quinine (b). The fragmentation spectrum of ions $[\mathrm{M}+\mathrm{H}]^{+}$confirms the paths of fragmentation obtained in the ESI-MS ${ }^{2}$ fragmentation of protonated quinine as reported by Kudlacek et al. [17] 
(a)

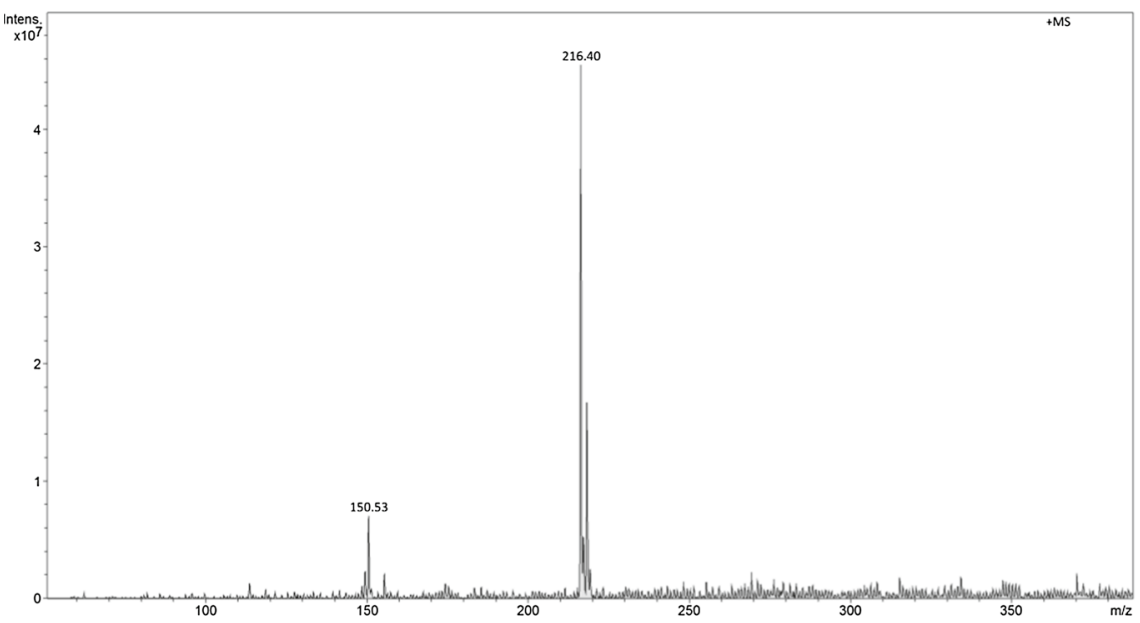

(b)

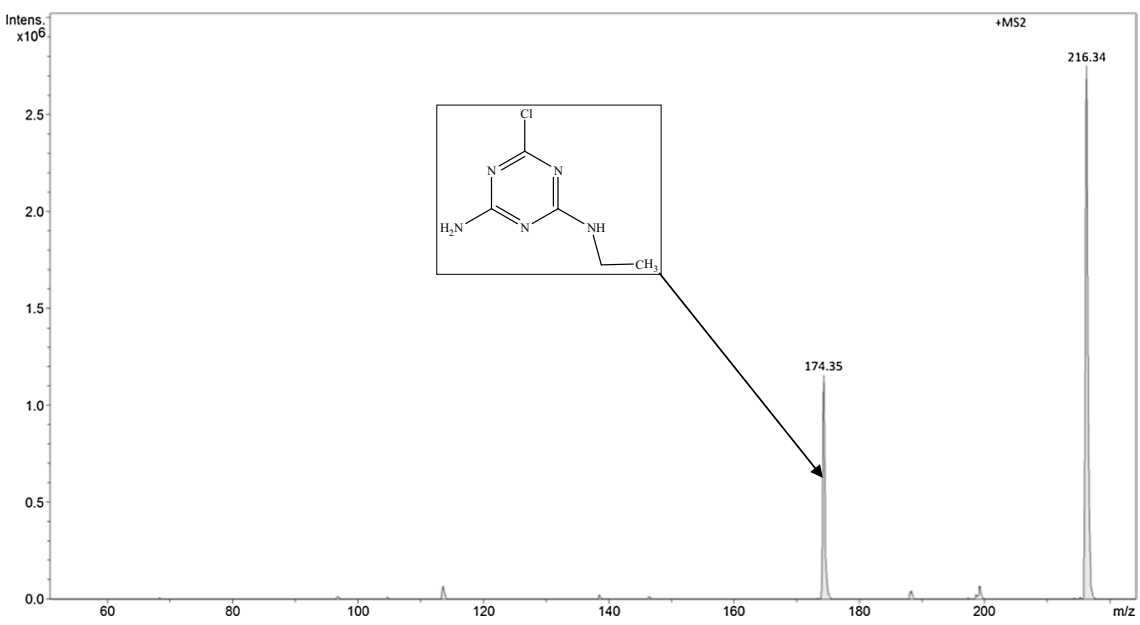

Fig. 7 The microwave argon plasma source-MS (positive ions) spectrum (a) and fragmentation (MS ${ }^{2}$ ) spectrum of atrazine direct from the atrazine-MIP $(\mathbf{b})$. The fragmentation spectrum of ions $[\mathrm{M}+\mathrm{H}]^{+}$confirms the paths of fragmentation obtained by Dong et al. [18]

samples such as biological and environmental samples. The analytes from the polymer structures thermally released into the argon plasma stream were ionized. The recorded microwave argon plasma ionization source-MS spectra (Figs. 7, 8 and 9) for these compounds (positive ions) showed an intense ion signal $[\mathrm{M}+\mathrm{H}]^{+}$while the fragmentation ions in the $\mathrm{MS}^{2}$ spectrum were characteristic of these compounds and additionally confirmed the correct $[\mathrm{M}+\mathrm{H}]^{+}$signal assignment. 
(a)

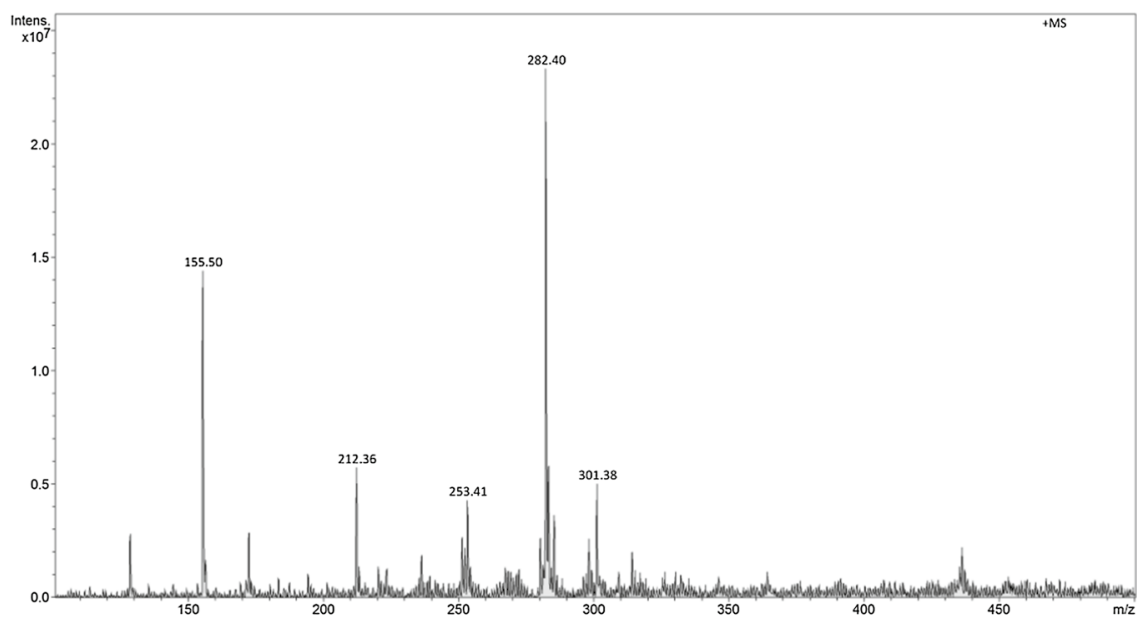

(b)

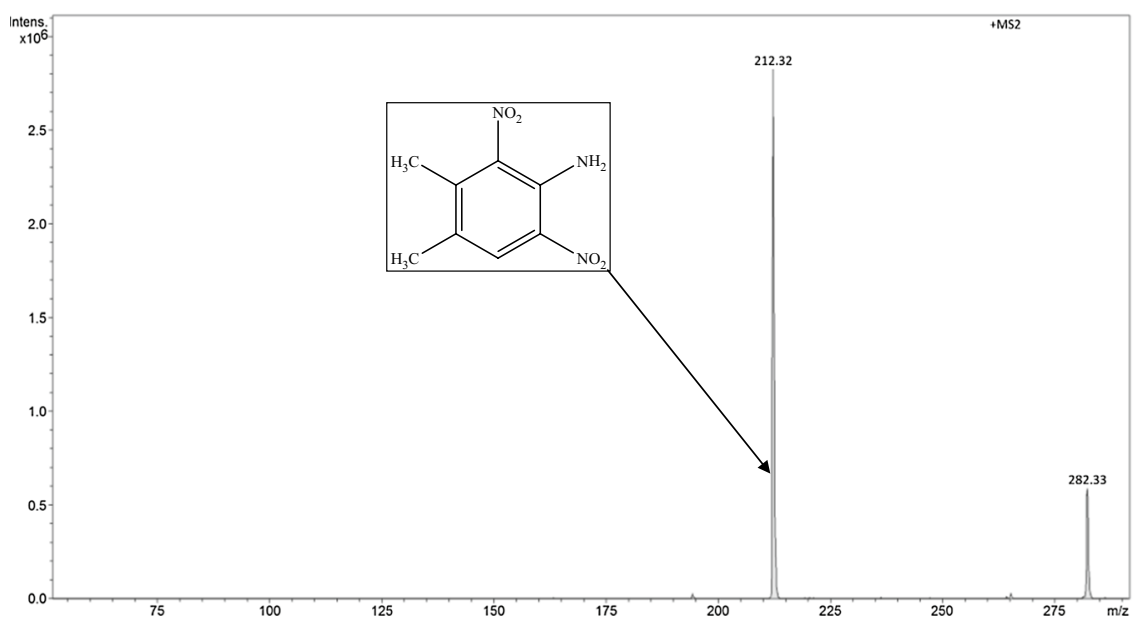

Fig. 8 The microwave argon plasma source-MS (positive ions) spectrum (a) and fragmentation (MS ${ }^{2}$ ) spectrum of pendimethalin direct from the pendimethalin-MIP (b)

The microwave argon plasma source-MS technique makes it possible to analyze compounds from complex matrices. The analyzed compounds are released from these matrices by thermal desorption and directed to the argon plasma stream. The active ingredients from commercial medical tablets were analyzed. Very good results were obtained for all studied systems (Figs. 10, 11 and 12). In the MS spectra (positive ions), intense signals were observed $\mathrm{m} / \mathrm{z}$ $[\mathrm{M}+\mathrm{H}]^{+}$, whereas the fragmentation spectra $\left(\mathrm{MS}^{2}\right)$ of ions $[\mathrm{M}+\mathrm{H}]^{+}$confirmed the structure of the analyzed analytes. 
(a)

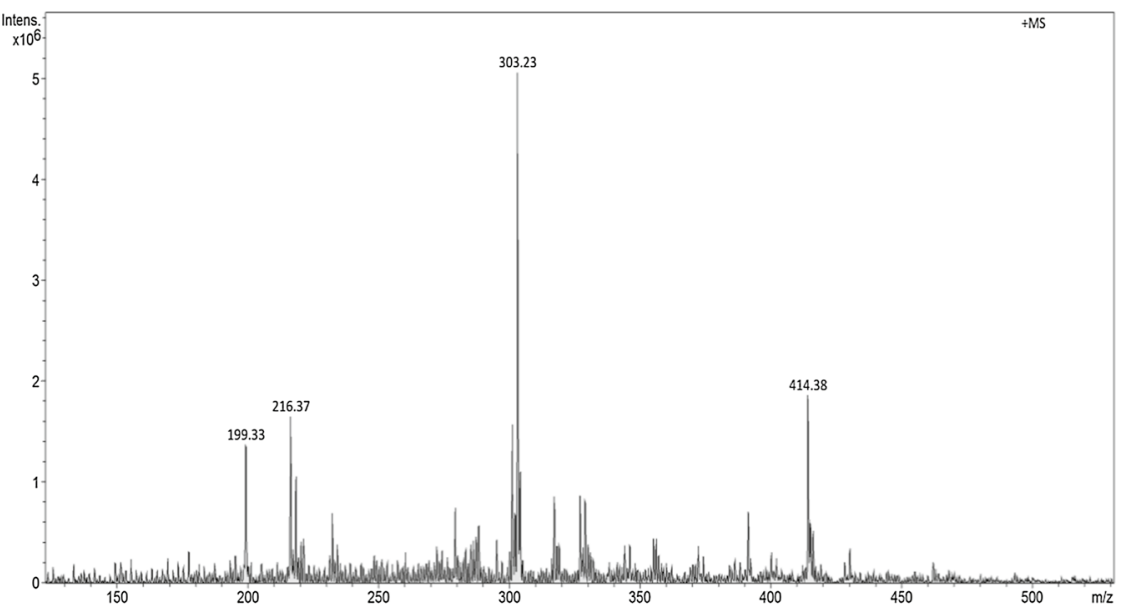

(b)

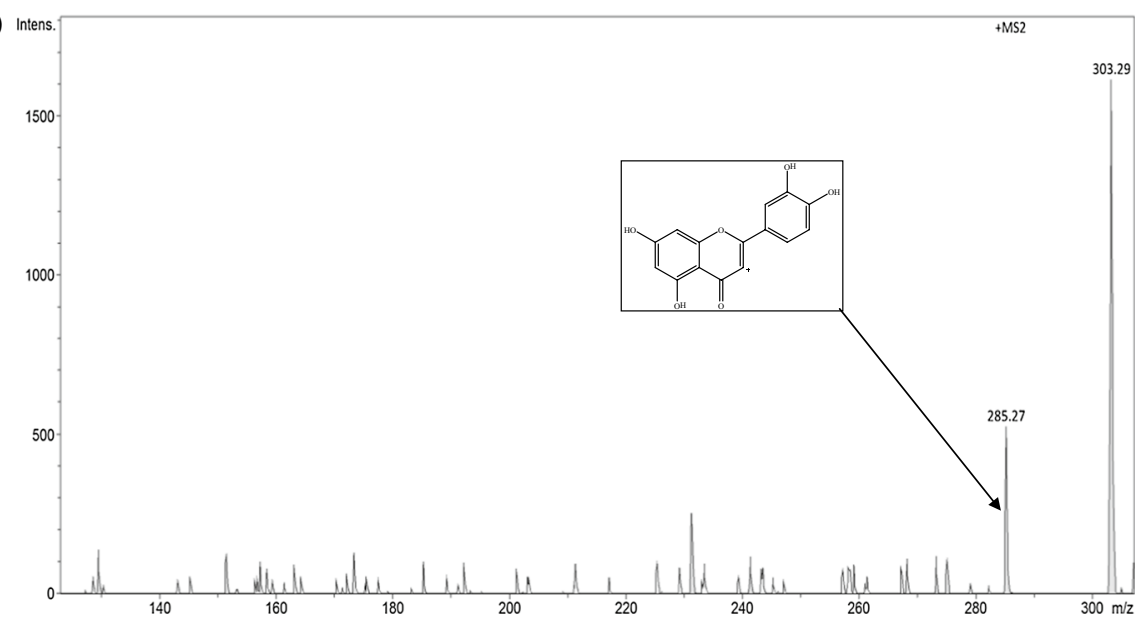

Fig. 9 The microwave argon plasma source-MS (positive ions) spectrum (a) and fragmentation (MS ${ }^{2}$ ) spectrum of quercetin direct from the quercetin-MIP (b)

For all tested systems: pure compounds, MIPs with absorbed analyte and medical tablets with active ingredients, the linear range of determinations and the limit of analyte detection were determined (Table 2).

The LOD value depended on the structure of the analyte and ranged from $0.002 \mu \mathrm{g}$ to $0.005 \mu \mathrm{g}$ for the analyzed compounds, and the LOQ value ranged from $0.006 \mu \mathrm{g}$ to $0.015 \mu \mathrm{g}$. 


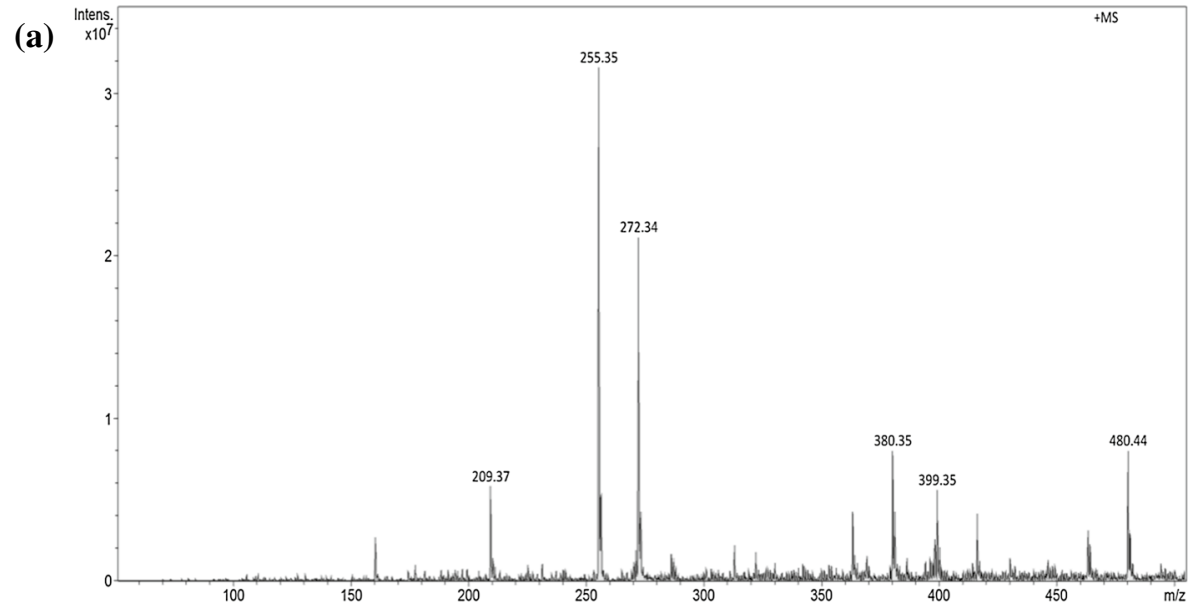

(b)

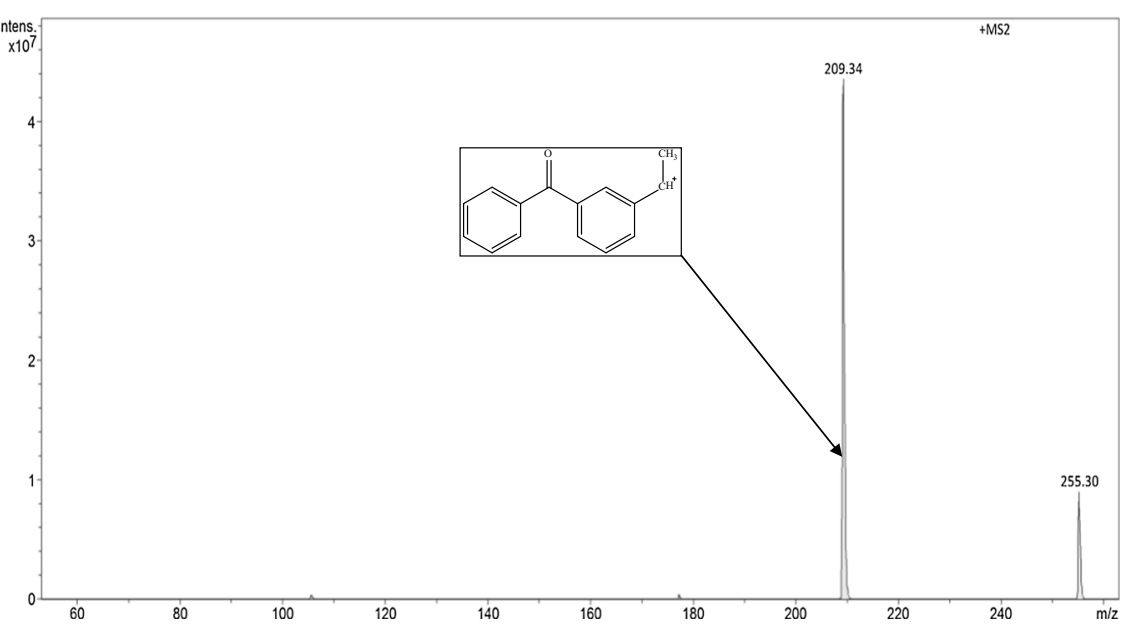

Fig. 10 The microwave argon plasma source-MS (positive ions) spectrum (a) and fragmentation $\left(\mathrm{MS}^{2}\right.$ ) spectrum of ketoprofen (b) direct from the medicine tablet

\section{Conclusion}

A new microwave argon plasma ionization source was designed and constructed for the use in ion trap mass spectrometry for analysis of solid samples and analytes on solid materials. The microwave plasma ionization source was used to generate argon plasma allowing the ionization of analyte particles thermally released from the heated crucible whose temperature could be regulated from 100 to $250{ }^{\circ} \mathrm{C}$. The system with a microwave 
(a)

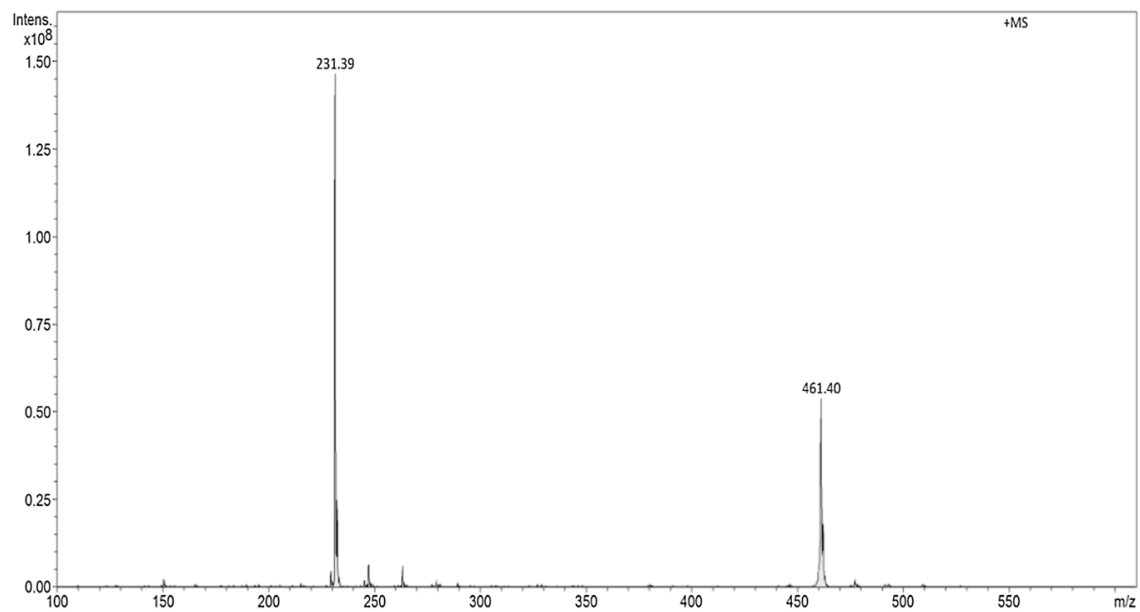

(b)

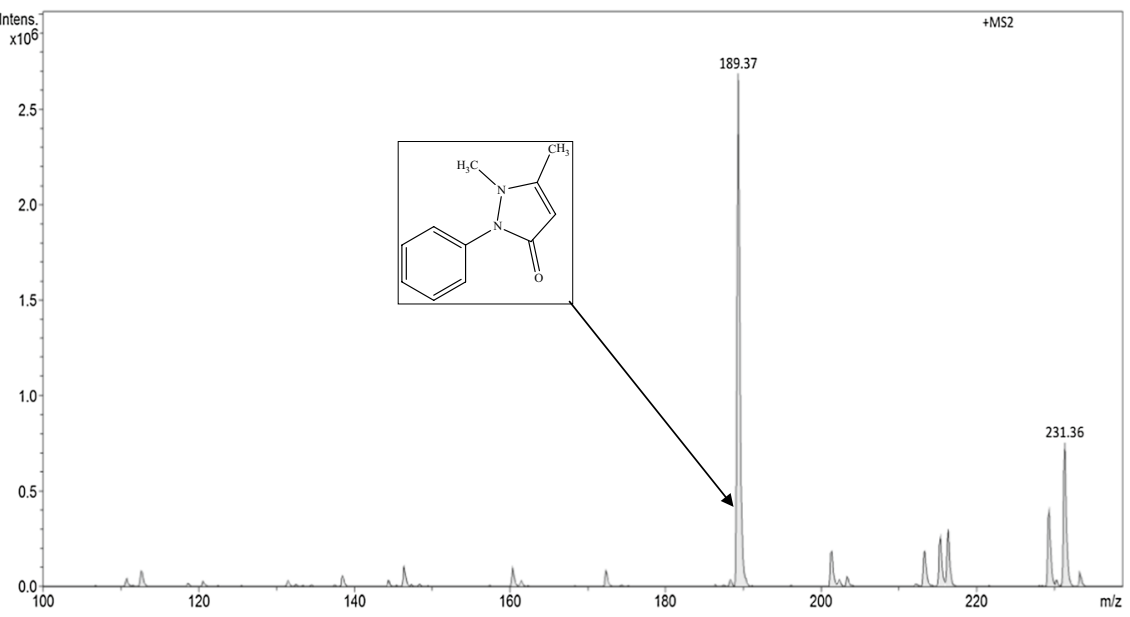

Fig. 11 The microwave argon plasma source-MS (positive ions) spectrum (a) and fragmentation $\left(\mathrm{MS}^{2}\right.$ ) spectrum of propyphenazone (b) direct from the medicine tablet

argon plasma torch was used to determine low molecular weight compounds from different matrices. The obtained results indicate that the proposed microwave burner with argon as the plasma gas, can be used in MS analysis in which the ionization source of samples is exchangeable. In the proposed method, analytes are thermally released from solid matrices without any sample preparation steps prior to qualitative and quantitative analysis. This method significantly reduces the time of analysis without analyte loss, as in the classical sample isolation by filtration or sludge spinning phases. 
(a)

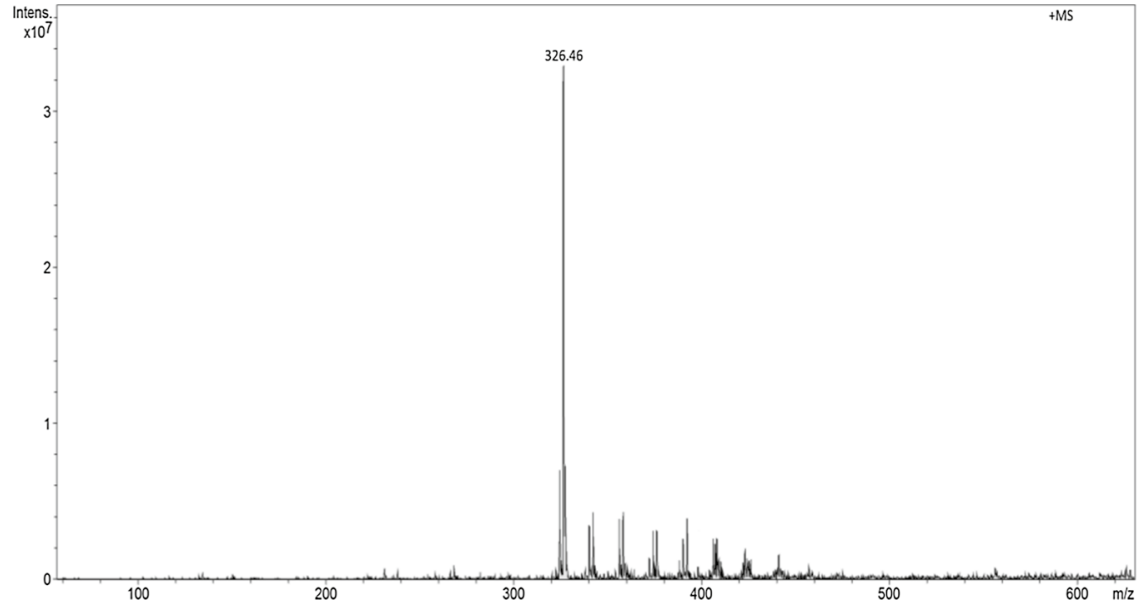

(b)

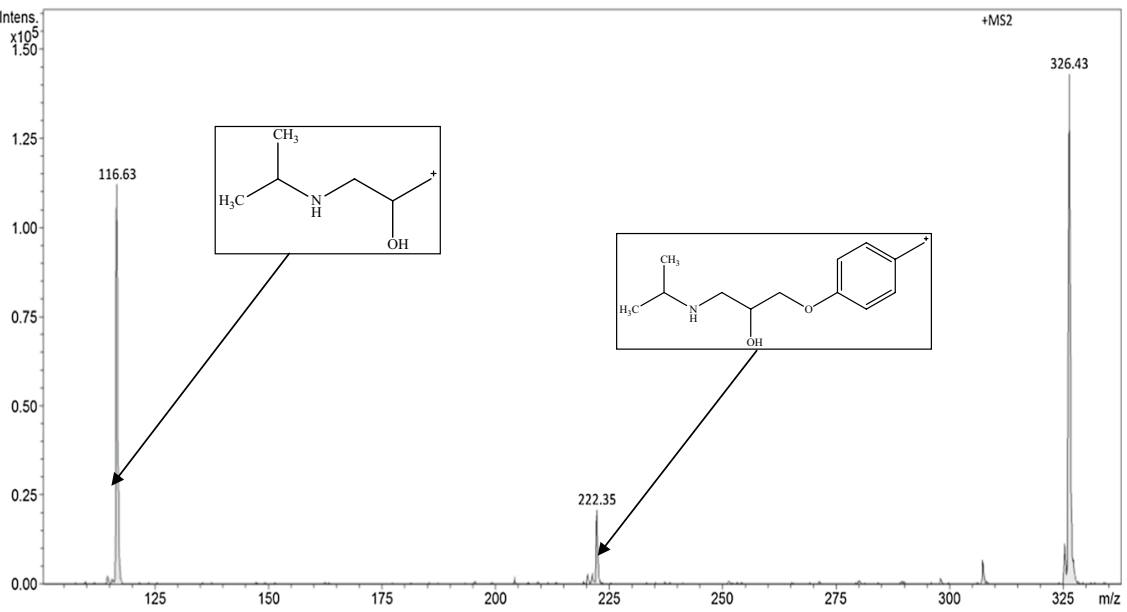

Fig. 12 The microwave argon plasma source-MS (positive ions) spectrum (a) and fragmentation $\left(\mathrm{MS}^{2}\right.$ ) spectrum of bisoprolol (b) direct from the medicine tablet. The fragmentation spectrum of ions $[\mathrm{M}+\mathrm{H}]^{+}$ confirms the paths of fragmentation obtained by M.F.Tutunji et al. [19]

Table 2 Comparison of analytical parameters for studied materials

\begin{tabular}{lllll}
\hline Analyte & Matrix & Linear range $(\mu \mathrm{g})$ & $\begin{array}{l}\text { LOD of analyte } \\
(\mu \mathrm{g})\end{array}$ & $\begin{array}{l}\text { LOQ of } \\
\text { analyte } \\
(\mu \mathrm{g})\end{array}$ \\
\hline Theophylline & Pure compounds & $0.008-3$ & 0.005 & 0.015 \\
Caffeine & Pure compounds & $0.008-3$ & 0.005 & 0.015 \\
Quinine & Pure compounds & $0.008-3$ & 0.005 & 0.015 \\
Atrazine & Analyte-MIP & $0.003-10$ & 0.002 & 0.006 \\
Pendimethalin & Analyte-MIP & $0.003-10$ & 0.002 & 0.006 \\
Quercetin & Analyte-MIP & $0.003-10$ & 0.002 & 0.006 \\
Ketoprofen & Drug in a tablet & $0.005-10$ & 0.003 & 0.009 \\
Propyphenazone & Drug in a tablet & $0.003-10$ & 0.002 & 0.006 \\
Bisoprolol & Drug in a tablet & $0.005-10$ & 0.003 & 0.009 \\
\hline
\end{tabular}


Acknowledgements This work was financially supported by the National Science Centre, Poland, under Grant Number 2016/21/B/ST4/02082.

Open Access This article is distributed under the terms of the Creative Commons Attribution 4.0 International License (http://creativecommons.org/licenses/by/4.0/), which permits unrestricted use, distribution, and reproduction in any medium, provided you give appropriate credit to the original author(s) and the source, provide a link to the Creative Commons license, and indicate if changes were made.

\section{References}

1. Badu-Tawiah AK, Eberlin LS, Ouyang Z, Cooks RG (2013) Chemical aspects of the extractive methods of ambient ionization mass spectrometry. Annu Rev Phys Chem 64:481-505

2. Gross JH (2014) Direct analysis in real time-a critical review on DART-MS. Anal Bioanal Chem 406:63-80

3. Javanshad R, Venter AR (2017) Ambient ionization mass spectrometry: real-time, proximal sample processing and ionization. Anal Methods 9(34):4896-4907

4. Smoluch M, Mielczarek P, Silberring J (2016) Plasma-based ambient ionization mass spectrometry in bioanalytical sciences. Mass Spectrom Rev 35:22-34

5. Huang Y, Huang Z, Watanabe C, Wang L (2019) Combined direct analysis in real-time mass spectrometry (DART-MS) with analytical pyrolysis for characterization of Chinese crude propolis. J Anal Appl Pyrolysis 137:227-236

6. Cunningham DD (2018) Analysis of trace drugs of abuse by direct analysis in real time (DART) mass spectrometry. In: Musah R (ed) Methods in molecular biology, vol. 1810. Humana Press, New York, pp 193-205

7. Smoluch M, Reszke E, Ramsza A, Labuz K, Silberring J (2012) Direct analysis of methcathinone from crude reaction mixture by flowing atmospheric-pressure afterglow mass spectrometry. Rapid Commun Mass Spectrom 26(13):1577-1580

8. Smoluch M, Mielczarek P, Reszke E, Hieftje GM, Silberring J (2014) Determination of psychostimulants and their metabolites by electrochemistry linked on-line to flowing atmospheric pressure afterglow mass spectrometry. Analyst 139(17):4350-4355

9. Cegłowski M, Kurczewska J, Smoluch M, Reszke E, Silberring J, Schroeder G (2015) Magnetic scavengers as carriers of analytes for flowing atmospheric pressure afterglow mass spectrometry (FAPAMS). Analyst 140(17):6138-6144

10. Smoluch M, Gierczyk B, Reszke E, Babij M, Gotszalk T, Schroeder G, Silberring J (2016) FAPA mass spectrometry of designer drugs. Talanta 146:29-33

11. Storey AP, Zeiri OM, Ray SJ, Hieftje GM (2017) Use of interrupted helium flow in the analysis of vapor samples with flowing atmospheric-pressure afterglow-mass spectrometry. J Am Soc Mass Spectrom 28(2):263-269

12. Song L, Evans-Nguyen T, Badal SP, Donovan J, Ayodeji I, MacLean GM, Vazquez T, Shelley JT (2019) Coupling flowing atmospheric pressure afterglow (FAPA) with differential mobility spectrometry-mass spectrometry (DMS-MS) for rapid analysis of solid metal complexes. Int J Mass Spectrom 438:157-165

13. García-Reyes JF, Vogel P, Marggraf U, Franzke J, Brandt S (2019) Analyte-tailored controlled atmosphere improves dielectric barrier discharge ionization mass spectrometry performance. Anal Chem 91(5):3733-3739

14. Zeiri OM, Storey AP, Ray SJ, Hieftje GM (2017) Microplasma-based flowing atmospheric-pressure afterglow (FAPA) source for ambient desorption-ionization mass spectrometry. Anal Chim Acta 952:1-8

15. Dai J, Zhao Z, Liang G, Duan Y (2017) A novel microwave-induced plasma ionization source for ion mobility spectrometry. Sci Rep 7(1):44051

16. Pfeuffer KP, White A, Broekaert JAC, Hieftje GM (2015) Afterglow of a microwave microstrip plasma as an ion source for mass spectrometry. Spectrochim Acta B At Spectrosc. 103-104:43-48

17. Kudláček K, Nesměrák K, Štícha M, Kozlík P, Babica J (2017) Historical injection solutions of quinine analyzed by HPLC/MS. Monatshefte fur Chem 148(9):1613-1618

18. Liang S, Dong X, Su M, Sun H (2016) Analysis of herbicide atrazine and its degradation products in cereals by ultra-performance liquid chromatography-mass spectrometry. Anal Methods 8(17):3599-3604 
19. Tutunji MF, Ibrahim HM, Khabbas MH, Tutunji LF (2009) Simultaneous determination of bisoprolol and hydrochlorothiazide in human plasma by HPLC coupled with tandem mass spectrometry. J Chromatogr B Anal Technol Biomed Life Sci 877(16-17):1689-1697

Publisher's Note Springer Nature remains neutral with regard to jurisdictional claims in published maps and institutional affiliations. 